Military Technical College Kobry Elkobbah, Cairo, Egypt

May 29-31,2012

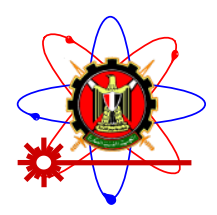

$6^{\text {th }}$ International Conference on

Mathematics and Engineering

Physics (ICMEP-6)

\title{
Application of Laser interference Technique to investigate Haematological Disorders
}

\section{H.EGhandoor,E.M.El-Said,A.Bayoumy and L.M.Zaki}

\author{
Physics department ,Faculty of Science ,Ain Shams University ,Cairo,Egypt \\ Fax :+202-24845940 \\ E-mail:helghandoor@hotmail.com \\ E-mail: dramanybayoumy@yahoo.com \\ E-mail:lobna_zaki@hotmail.com
}

\begin{abstract}
:
In this work laser interference technique was used to detect haematological disorders such as anaemia ,thrombocoytopenia ,leucocytosis this technique is called the laser sheet interference technique developed by professor Hatem El Ghandoor for measuring the optical density of blood components, the obtained results applying by this technique proved that The laser interference technique could be used as a very sensitive tool for measuring haemoglobin of blood and It may be considered as the basis for designing a new prototype to measure haemoglobin based on a laser interference
\end{abstract}

Keywords: haematological disorder, laser interferometry ,laser-sheet interferometry Reference to this paper should be made as follow :El Ghandoor, H.,El Said,A.M., Bayoumy,A.,Zaki,L.M. (2010) 'Application of laser interferometry to investigate haematological disorders

\section{Introduction}

In our work we have used a technique was recently developed to examine optical fibres (El Ghandoor et al.,1999,2000),crude oil samples filling the capillary tube .we used capillary tube of diameter $\leq 1 \mathrm{~mm}$, this makes the expense for one measurement of blood component very cheap ,it differs from other capillary tube methods in that the laser impinges on the capillary tubes in a form of a sheet that covers the whole width of the capillary tube as opposed to a single narrow beam hitting particular areas.consequently, a transverse interference fringes will be formed in a vertical arrangement localized at locations directly related to the angles of deflection of the laser 
Military Technical College Kobry Elkobbah, Cairo, Egypt May 29-31,2012

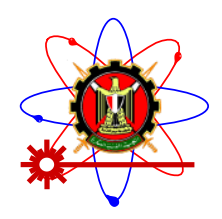

$6^{\text {th }}$ International Conference on

Mathematics and Engineering

Physics (ICMEP-6)

sheet and hence is related to the optical path length inside the blood sample filling the capillary tube this optical path length is directly proportional to the refractive index of the blood sample filling the capillary tube .

This method is applied to blood sample for measuring their refractive indices with accuracy up to $10^{-6}$. The ray tracing inside the capillary tube-laser lens interferometer is presented and the resulting interference patterns were interpreted the relationship between haemoglobin,white blood cells ,red blood cells and platelets in the blood sample and their refractive indices is obtained experimentally and theoretical representation is given also.

we used this technique to investigate haematological disorders which causes as a result of a decrease in the red or white blood cells or an increase of blood cells that may not be working normally. Another problem includes a disturbance in the clotting ability of the blood, which can lead to abnormal bruising or bleeding. Sometimes the blood may clot (thrombose) within normal blood vessels for no apparent reason and deprive a part of the body of its blood supply and those disorders causes some diseases such as anaemia ,thrombocoytopenia,leucocytosis ,

Anaemia is a reduced level of haemoglobin in the blood. Haemoglobin, (contained in the red blood cells) obtains oxygen from the lungs and carries it to all the bodys' cells. Here it is used as fuel in the metabolism of sugar and fat to produce energy, so, when the level of oxygen in the blood is reduced, tiredness and other symptoms of anaemia result. To produce red blood cells, the body needs (among other things) iron, vitamin B12 and folic acid. If there is a lack of one or more of these ingredients, anaemia will develop. Anaemia is a common and potentially dangerous condition of the blood brought about when the body does not produce enough red blood cells.

Anemia is a condition characterized by abnormally low levels of healthy red blood cells or hemoglobin (the component of red blood cells that delivers oxygen to tissues throughout the body).

The tissues of the human body need a regular supply of oxygen to stay healthy. Red blood cells, which contain hemoglobin that allows them to deliver oxygen throughout the body, live for only about 120 days. When they die, the iron they contain is returned to the bone marrow and used to create new red blood cells. Anemia develops when heavy bleeding causes significant iron loss or when something happens to slow down the production of red blood cells or to increase the rate at which they are destroyed 
Military Technical College

Kobry Elkobbah,

Cairo, Egypt

May 29-31,2012

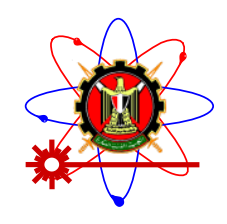

$6^{\text {th }}$ International Conference on

Mathematics and Engineering

Physics (ICMEP-6)

Many typed of haemoglobin meters are commercially available in the present work ,here we describe a simple interferometric technique for accurate measurement of haemoglobin concentration in blood,the main feature of this technique is to relate blood refractive index to its haemoglobin level This technique is very sensitive for measuring haemoglobin concentration in blood,It has the potential to be an important accurate medical tool in the future

Thrombocytopenia is a lower than normal number of platelets in the blood. Platelets are one of the components of the blood along with white and red blood cells. Platelets play an important role in clotting and bleeding. Platelets are made in the bone marrow similar to other cells in the blood such as, white blood cells and red blood cells. Platelets originate from megakaryocytes which are large cells found in the bone marrow. The fragments of these megakaryocytes are platelets that are released into the blood stream. The circulating platelets make up about two third of the platelets that are released from the bone marrow. The other one third is typically stored (sequestered) in the spleen.

Platelets, in general, have a brief 7 to 10 days life in the blood, after which they are removed from the blood circulation. The number of platelets in the blood is referred to as the platelet count and is normally between 150,000 to 450,000 per micro liter (one millionth of a liter) of blood. Platelet counts less than 150,000 are termed thrombocytopenia. Platelet counts greater that 450,000 are called thrombocytosis.

The function of platelets is very important in the clotting system. Platelets are a part of a very complicated pathway. They circulate in the blood vessels and become activated if there is any bleeding or injury in the body. Certain chemicals are released from the injured blood vessels or other structures that signal platelets to become activated and join the other components of the system to stop the bleeding. When activated, the platelets become sticky and adhere to one another and to the blood vessel wall at the site of the injury to slow down and stop the bleeding by plugging up the damaged blood vessel or tissue (hemostasis).

It is important to note that, even though, the platelet numbers are decreased in thrombocytopenia, their function usually remains completely intact. Other disorders exist that can cause impaired platelet function despite normal platelet count.

Low platelet count in severe cases may result in spontaneous bleeding or may cause delay in the normal process of clotting. In mild thrombocytopenia, there may be no adverse effects in the clotting or bleeding pathways.

Leukocytosis refers to an increase in the total number of WBCs due to any cause., leukocytosis is traditionally classified according to the component of white cells that contribute to an increase in 
Military Technical College

Kobry Elkobbah,

Cairo, Egypt

May 29-31,2012

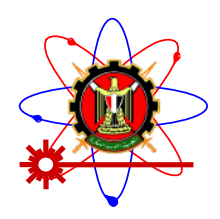

$6^{\text {th }}$ International Conference on

Mathematics and Engineering

Physics (ICMEP-6)

the total number of WBCs. Therefore, leukocytosis may be caused by an increase in neutrophil count, lymphocyte count, monocyte count, eosinophilic granulocyte count, basophilic granulocyte count, or immature cells. A combination of any of the above may be involved.

Leukocytosis can be a reaction to various infectious, inflammatory, and, in certain instances, physiologic processes (eg, stress, exercise). This reaction is mediated by several molecules, which are released or upregulated in response to stimulatory events that include growth or survival factors (eg, granulocyte colony-stimulating factor, granulocyte-macrophage colonystimulating factor, c-kit ligand), adhesion molecules (eg, CD11b/CD18), and various cytokines (eg, interleukin-1, interleukin-3, interleukin-6, interleukin-8, tumor necrosis factor).

The peripheral leukocyte count is determined by several mechanisms, including the size of precursor and storage pool of myeloid and lymphoid cells, the rate of release of the cells from the storage pool in the bone marrow, the rate of marginating cells out of blood vessels into the tissues, and the rate of consumption of the cells in the tissues (ie, cell loss). The growth factors, adhesion molecules, and cytokines control all 4 mechanisms.

\section{Experimental set-up}

Figure 1 shows the experimental setup .A He-Ne laser of $632.8 \mathrm{~nm}$ wavelength was used as the light source .after a spatial filter and collimating lens, a parallel beam with nearly $10 \mathrm{~cm}$ diameter was obtained ,the cylindrical lens was made of K-9 glass of refractive index 1.5163 , whose focal length is $31.2 \mathrm{~cm}$ the inner and outer diameters of capillary tube 0.9 and 1.2 $\mathrm{mm}$, respectively. It should be clear that the capillary tube is totally immersed in the laser sheet of light. The width of the focused beam is less than $1 \mathrm{~mm}$, which is very small comparaed with the diameter of the capillary tube the capillary tube is parallel to and within the focal lines of the cylindrical lens .

Due to the variation of the optical path length of rays passing through the capillary tube, multiple reflections and refractions of light waves takes place through the capillary tube-lens interferometer. Interference of these waves with the waves passing outside the tube leads to constructive and destructive interference, producing transverse interference fringe pattern (TIP). This fringe pattern displays he refractive index information of the sample inside the capillary tube.

The rays passing through the capillary tube formed an interference pattern on the screen at the same time we also observed the interference pattern formed by the reflected light of the first two walls of the capillary tube. This fringe pattern will be reflected by the cylindrical lens and 
Military Technical College

Kobry Elkobbah,

Cairo, Egypt

May 29-31,2012

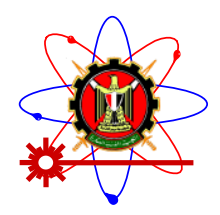

$6^{\text {th }}$ International Conference on

Mathematics and Engineering

Physics (ICMEP-6)

superimposed on the fringe pattern formed by the transmission rays .this will influence the contrast of the fringe pattern so a diaphragm was put on the left of the capillary tube .

High performance CCD camera recorded the interference pattern, which was stored in a computer for later digital processing .The desired part of the fringe pattern can be selected and processed with an image enhancing computer program the enhanced pattern is compared with a theoretically estimated one .

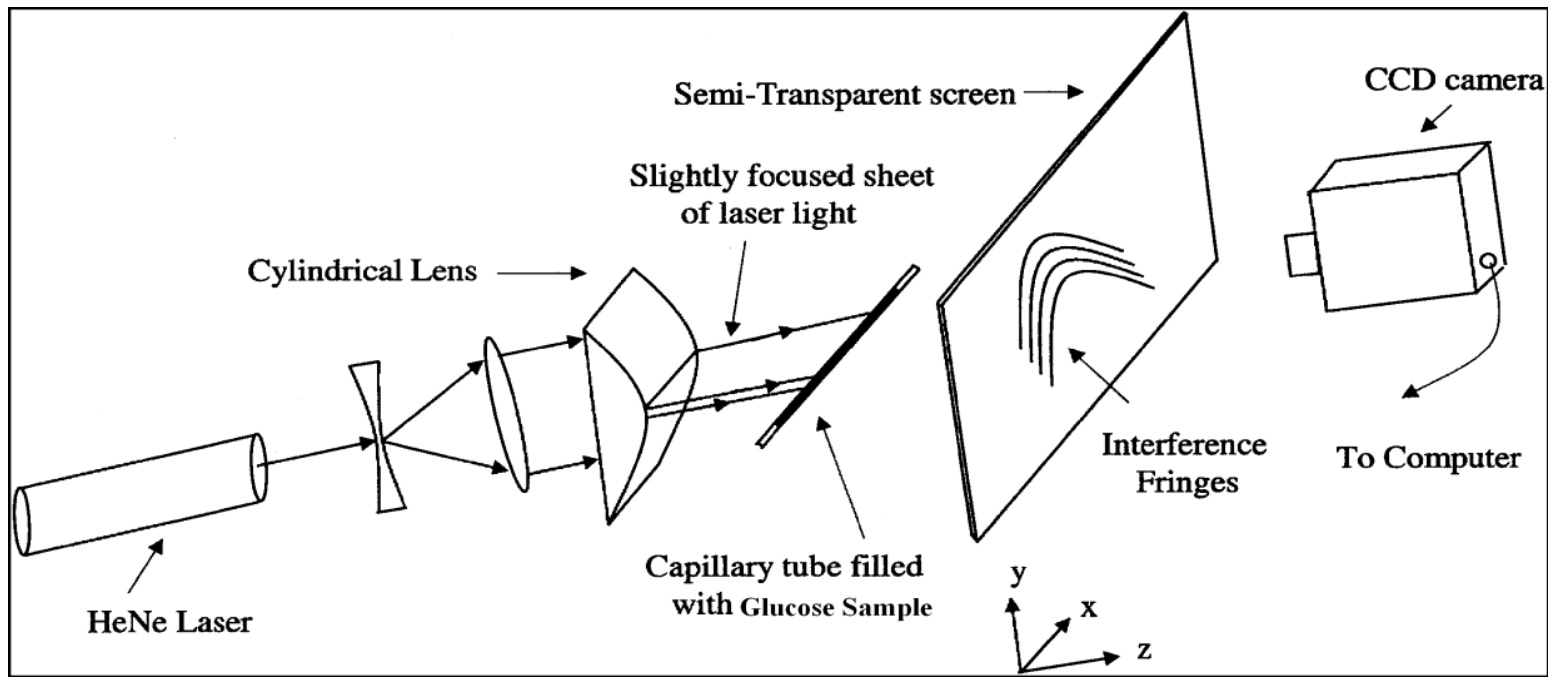

Fig. (1) Schematic diagram of the experimental setup

Tweleve blood samples were taken from men and women were obtained by aspiration puncture of a slightly congested cubital vein by a physician to obtain the complete blood count for the patient which is one of the most commonly ordered blood tests. The complete blood count is the calculation of the cellular (formed elements) of blood. These calculations are generally determined by special machines that analyze the different components of blood in less than a minute.

The complete blood count (CBC) test is performed by obtaining a few milliliters (one to two teaspoons) of blood sample directly form the patient. It can be done in many settings including the doctor's office, laboratories, and hospitals. The skin is wiped clean with an alcohol pad, and then a needle is inserted through the area of cleansed skin into to patient's vein (one that can be visualized from the skin.) The blood is then pulled from the needle by a syringe or by a 
Military Technical College Kobry Elkobbah, Cairo, Egypt May 29-31,2012

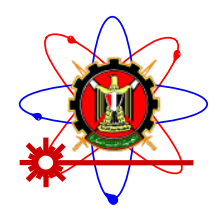

$6^{\text {th }}$ International Conference on

Mathematics and Engineering

Physics (ICMEP-6)

connection to a special vacuumed vial where it is collected. This sample is then taken to the laboratory for analysis.

We used the data in $\mathrm{CBC}$ to get the relationship between blood component such as haemoglobin, red blood cells, white blood cells, and platelets concentration with the refractive index

\section{Theoretical model}

Recently, a new method, which was called the capillary tube interferometer method was used to measure the refractive index of a low transparent liquid this method was also used to measure the refractive index of fiber by El-Ghandoor . another research after that used a similar experimental setup to measure the refractive index of thick fiber.and they called this method the lens-fiber interference method .In all these references, the experimental setup was similar ,but the theoretical analysis was different .

El-Ghandoor and co-workers took the focused laser sheet of light as a parallel beam and made a theoretical analysis the parallel beams cannot produce a bell-shaped fringe pattern ,but the focused laser sheet beam can .the ray tracing model was quite different .In Ref. 1, the authors proposed three possible interference pairs of rays passing through the capillary tube (see fig .1).

The interference fringe can be formed between ray 3, which passes entirely through the wall of the capillary tube and ray 6 , which passes perpendicularly through the middle of the capillary tube ,or ray 5, which enters the oil medium at an angle ,and ray 2, which is one of the nonrefracted rays that passes through the air on top of the capillary tube ,or ray 4 ,a ray suffers total internal reflection at the glass-oil interface , and ray 1, which passes on top of the capillary tube .But according to Ref 2 interference takes place between ray 1 passing through the air of the capillary tube, or ray 2 passing through the cladding-core-cladding and ray 3 (see fig. 2). 
Military Technical College Kobry Elkobbah, Cairo, Egypt May 29-31,2012

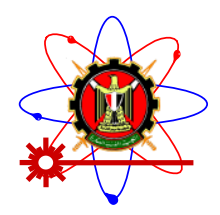

$6^{\text {th }}$ International Conference on

Mathematics and Engineering

Physics (ICMEP-6)

Hamza et al and Ramadan used a similar, experimental set up to measure the refractive index of thick step index fiber .the focused beam width was less than the fiber diameter .the fringe pattern of Ramadan was different from that of El-Ghandoor whose fringe was steeply bell shaped ,but that of Hamza and Ramadan was slightly bell shaped .

Hamza and Ramadan explained that the fringe was relative to the aberrated cylindrical lens.the fiber was located in front of a cylindrical lens parallel to its axis and perpendicular to the optical axis .

Due to its aberration of the lens ,the emerged light would not have an ideal line ,but a series of parallel lines the parallel rays were previously incident on the cylindrical lens near the optical axis while they emerged toward the optical axis but the rays were previously incident on the cylindrical lens awy from the optical axis, so the emerged light was divided into two parts .these two parts will leave the fiber to overlap with each other and produce two beam interference on the screen. Also, the theoretical analysis on the formation of the fringe pattern is different in Refs 1 and 3 and refs 4 and 5 .For the formation of the fringe.

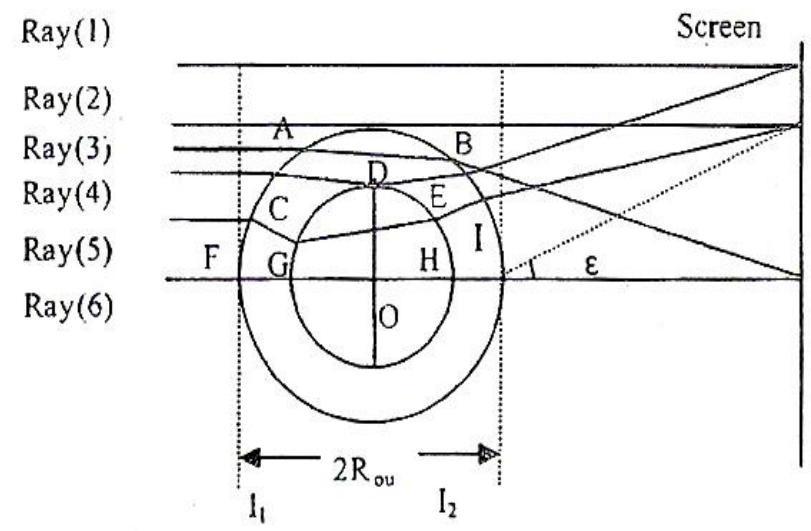

Fig. 1. Ray tracing of selected rays impinging on the upper semisphere of the capillary tube. The locations of three possible fringes are shown on the screen at right (Fig. 3 in Ref. 1).

we assumed a similar experimental setup, but the fiber was replaced by capillary tube filled with liquid sample .the cylindrical lens was taken as a glass medium with two interfaces. By using Snell's law and the ray-tracing method, the optical path of the incident beam was calculated 
Military Technical College

Kobry Elkobbah,

Cairo, Egypt

May 29-31,2012

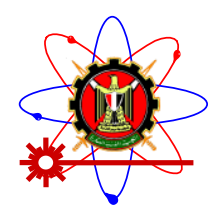

$6^{\text {th }}$ International Conference on

Mathematics and Engineering

Physics (ICMEP-6)

from the relation between the the optical path and the incident beam position,we found that there is an inverse point in the cylindrical lens divided the incident beam into two parts .

these two parts will pass through the capillary tube to overlap with each other and produce two beam interference on the screen .Furthermore, a computer program to directly compare the experimental and theoretical fringes was established .

By using this program and by comparing the experimental and theoretical fringes ,the refractive index of the liquid can be given when the two fringes coincides best. we measured the refractive index of several liquids by using the capillary tube interferometer method and an Abbe's refractometer. A comparasion of the results shows that the accuracy of the two methods is approximately the same .

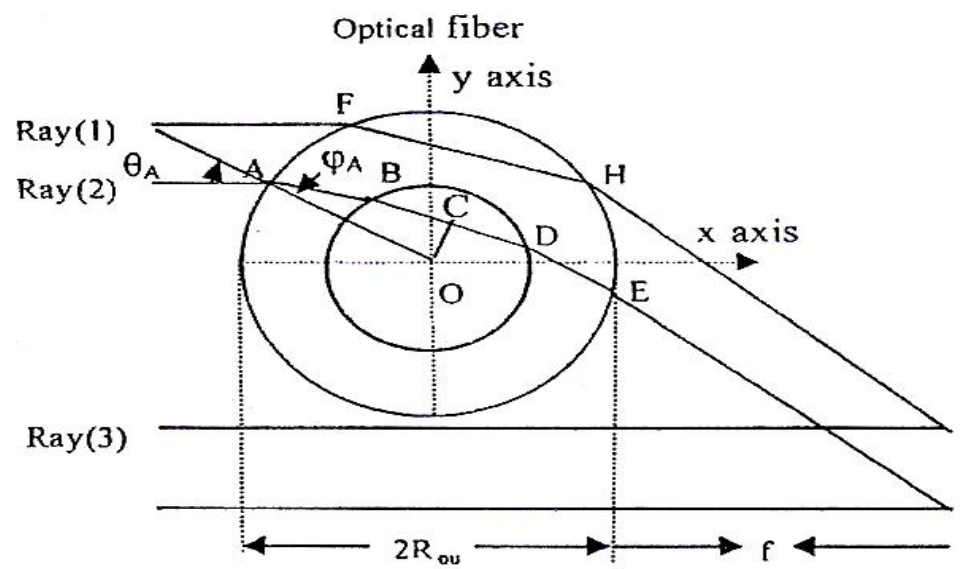

Fig. 2. Ray tracing inside the optical fiber and in the surrounding medium where $A\left(X_{A}, Y_{A}\right), B\left(X_{B}, Y_{B}\right), D\left(X_{D}, Y_{D}\right), F\left(X_{F}, Y_{F}\right)$, and $H\left(X_{H}, Y_{H}\right)$ (Fig. 2 in Ref. 2).

\section{Theory}

For capillary tube located in a fixed position at a definite distance from the cylindrical lens ,the ray position on the screen will be a function of $y$,where $y$ is the distance between the incident ray on the cylindrical lens and the optical axis (see fig 4).the optical path of a ray with a y value can be calculated according to fig 4 . from the plane at the tangent plane of the curved surface of the cylindrical lens to the screen, the OPL of the ray can be calculated as follows

$$
\mathrm{OPL}=M A n_{a}+A B n_{c y}+B C n_{a}+2 C D n_{g}+D E n+F G n_{a}
$$

Where 
Military Technical College Kobry Elkobbah, Cairo, Egypt May 29-31,2012

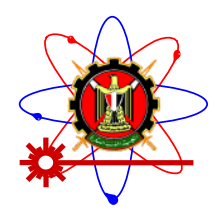

$6^{\text {th }}$ International Conference on Mathematics and Engineering Physics (ICMEP-6)

$\mathrm{n}_{\mathrm{a}}$ is the refractive index of air, $\mathrm{n}_{\mathrm{cy}}$ is the refractive index of the cylindrical lens and $\mathrm{n}_{\mathrm{g}}$ and $\mathrm{n}$ are the refractive indices of the tube and the investigated liquid . according to the geometry of fig 4 and Snell's law ,the OPL can be obtained gradually as follow :

The length of $M A$ equals

$$
\text { v } \quad M A=R_{c y}-\longdiv { R _ { c y } ^ { 2 } - y ^ { 2 } }
$$

Where

$\mathrm{R}_{\mathrm{cy}}$ is the curvature radius of the cylindrical lens and $\mathrm{y}$ is the distance between the incident ray on the cylindrical lens and the optical axis .

Consider a ray incident at a point $A$ with incident angle $\theta_{\mathrm{A}}$,

where

$\theta_{A}=-\arcsin \left(y_{A} / R_{c y}\right)$.

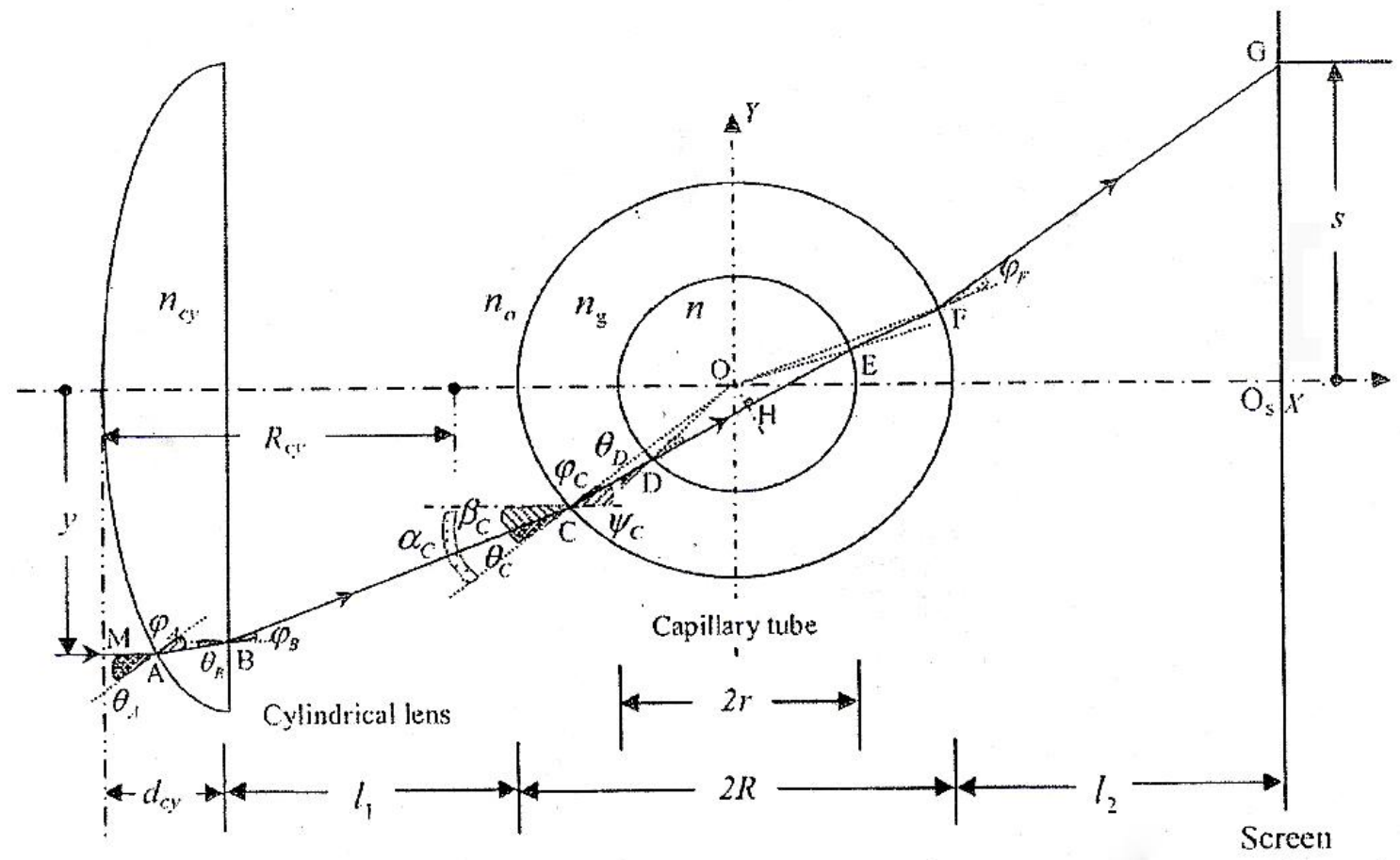

Fig. 4. Schematic diagram represents the path of the incident beam passing through the capillary tube.

the refractive angle of point $\mathrm{A}$ is $\Phi_{A}=\arcsin \left(n_{a} \sin \theta_{A} / n_{c y}\right)$.the corrdinate of $\mathrm{A}$ are

$$
\mathrm{X}_{A}=-\left[\sqrt{R_{c y}{ }^{2}-y_{A}{ }^{2}}+\left(R+I_{1}+d_{c y}-R_{c y}\right)\right]
$$


Military Technical College Kobry Elkobbah, Cairo, Egypt May 29-31,2012 $6^{\text {th }}$ International Conference on Mathematics and Engineering

Physics (ICMEP-6)

$$
Y_{A=y}
$$

where $\mathrm{R}$ is the outer radius of the capillary tube , $\mathrm{I}_{1}$ is the distance between the plane of the cylindrical lens and the wall of the capillary tube and $\mathrm{d}_{\mathrm{cy}}$ is the thickness of the cylindrical lens .

At point $\mathrm{B}$, the incident and refractive angles are

$$
\theta_{B}=-\left(\theta_{A}-\Phi_{A}\right) \text { and } \Phi_{B}=\arcsin \left(n_{c y} \sin \theta_{B} / n_{a}\right) \text {. }
$$

respectively .

the coordinates of point $\mathrm{B}$ are

$$
\begin{gathered}
X_{B}=-\left(R+I_{l}\right), \\
Y_{B}=K_{A B}\left(X_{B}-X_{A}\right)+Y_{A},
\end{gathered}
$$

Where $\mathrm{K}_{\mathrm{AB}} \tan \left(\theta_{\mathrm{A}}-\Phi_{\mathrm{A}}\right)$ is the slope of the line AB. SoAB $=\sqrt{\left(X_{A}-X_{B}\right)^{2}+\left(Y_{A}-Y_{B}\right)^{2}}$.Similarly ,the slope of the line $\mathrm{BC}$ is $\mathrm{K}_{\mathrm{BC}}=$-tan $\Phi_{\mathrm{B}}$, According to the equations of line $B C\left(y=K_{B C} X\right.$ $+b_{1}$, where $\left.b_{1}=y_{B}-K_{B C} X_{B}\right)$, and outside the circle of the capillary tube $\left(X^{2}+Y^{2}=R^{2}\right)$, the coordinates of point $\mathrm{C}$ can be given by

$$
\begin{aligned}
& x_{C}=\frac{-K_{B C} b_{1}-\sqrt{R^{2}+K_{B C}^{2} R^{2}-b_{1}^{2}}}{1+K_{B C}^{2}} \\
& Y_{C}=K_{B C} X_{C}+b_{1}
\end{aligned}
$$

The incident and refractive angles at point $C$ are $\Theta_{c}=\alpha_{C}+\beta_{C}$ and $\Phi_{C}=\arcsin \left(n_{a}\right.$ sin $\theta_{\mathrm{C}} / \mathrm{n}_{\mathrm{g}}$ ), respectively, where $\alpha_{\mathrm{C}}=\arctan \left(\mathrm{Y}_{\mathrm{C}} / \mathrm{X}_{\mathrm{C}}\right)$ and $\beta_{\mathrm{C}}=\Phi_{\mathrm{B}}$ (in this context,$\alpha_{\mathrm{i}}(\mathrm{i}=\mathrm{C}, \mathrm{D})$ are the angles between the horizontal and the normal lines and $\beta_{\mathrm{i}}(\mathrm{i}=\mathrm{C}, \mathrm{D})$ are the angles between the horizontal lines and the optical rays. The length of $\mathrm{BC}$ is

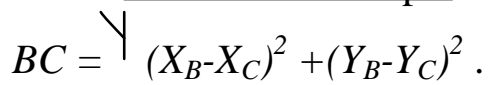

In the same way, the incident angle $\theta_{\mathrm{D}}$ and refractive angle $\Phi_{\mathrm{D}}$ at point $\mathrm{D}$ can be obtained,

$\theta_{D}=-\left(\alpha_{D}+\beta_{D}\right)$

$\alpha_{D}=\arctan \left(Y_{D} / X_{D}\right), \beta_{D=} \Psi_{C}, \Psi_{C}=-\left(\alpha_{C}+\Phi_{C}\right)$

and $\Phi_{D}=\arcsin \left(\mathrm{n}_{\mathrm{g}} \sin \theta_{\mathrm{D}} / \mathrm{n}\right)$.the coordinate of point $\mathrm{D}$ are

$$
\mathrm{X}_{\mathrm{D}}=-\frac{-K_{C D}-\sqrt{r^{2}+K_{C D}^{2} r^{2}-b_{2}^{2}}}{10}
$$


Military Technical College Kobry Elkobbah, Cairo, Egypt May 29-31,2012 $6^{\text {th }}$ International Conference on Mathematics and Engineering

Physics (ICMEP-6)

\section{$1+K_{C D}^{2}$}

$$
Y_{D}=K_{C D} X_{D}+b_{2}
$$

The length of $C D$ is $C D=\sqrt{\left(X_{C}-X_{D}\right)^{2}+\left(Y_{C}-Y_{D}\right)^{2}}$. because point $C$ and $F$ are symmetrical to $O$ ,CD is equal to $\mathrm{EF}$.the slope of line $\mathrm{DE}$ is $\mathrm{k}_{\mathrm{DE}}=-\tan \left(-\Theta_{\mathrm{D}}+\beta_{\mathrm{D}}+\Phi_{\mathrm{D}}\right)$, the coordinate of point $\mathrm{E}$ are

$$
\begin{aligned}
& X_{E}=\frac{-K_{D E} b_{3}-\sqrt{R_{i n}^{2}+K_{D E}^{2} R_{i n}^{2}-b_{3}^{2}}}{1+K_{D E}^{2}} \\
& Y_{E}=K_{D E} X_{E}+b_{3},
\end{aligned}
$$

Where $\mathrm{b}_{3}=\mathrm{Y}_{\mathrm{D}}-\mathrm{K}_{\mathrm{DE}} \mathrm{X}_{\mathrm{D}}$, the length of DE is DE $=\sqrt{\left(X_{D^{-}} X_{E}\right)^{2}+\left(Y_{D^{-}} Y_{E}\right)^{2}}$.

Assume that $\mathrm{OH}$ is vertical to $\mathrm{CF}$, the length $\mathrm{FG}$ and the distance $\mathrm{S}$ between the ray on the screen and the optical axis are as follows:

$$
\begin{aligned}
\mathrm{FG} & =\frac{\left(I_{2}-X_{F}\right)}{\operatorname{Cos}\left(\Phi_{F}-\alpha_{F}\right)} \\
\mathrm{S} & =\left(I_{2}-X_{F}\right) \tan \left(\Phi_{F}-\alpha_{F}\right)+Y_{F}
\end{aligned}
$$

Where $I_{2}$ is the distance between the screen and the wall of the capillary tube, $\Phi_{\mathrm{F}}$ is the refractive angle at point $\mathrm{F}, \Phi_{\mathrm{F}}=-\theta_{\mathrm{c}}$,

$\alpha_{\mathrm{F}}=\arctan \left(\mathrm{Y}_{\mathrm{F}} / \mathrm{X}_{\mathrm{F}}\right), \mathrm{X}_{\mathrm{F}}=2 \mathrm{X}_{\mathrm{H}}-\mathrm{X}_{\mathrm{C}}, \mathrm{Y}_{\mathrm{F}}=2 \mathrm{Y}_{\mathrm{H}}-\mathrm{Y}_{\mathrm{C}}$ and

$$
\begin{aligned}
& X_{H}=\frac{-K_{C F}\left(Y_{C}-K_{C F} X_{C}\right)}{1+K_{C F}^{2}} \\
& Y_{H}=\frac{Y_{C}-K_{C F} X_{C}}{1+K_{C F}^{2}}
\end{aligned}
$$


Military Technical College Kobry Elkobbah, Cairo, Egypt May 29-31,2012 $6^{\text {th }}$ International Conference on Mathematics and Engineering

Physics (ICMEP-6)

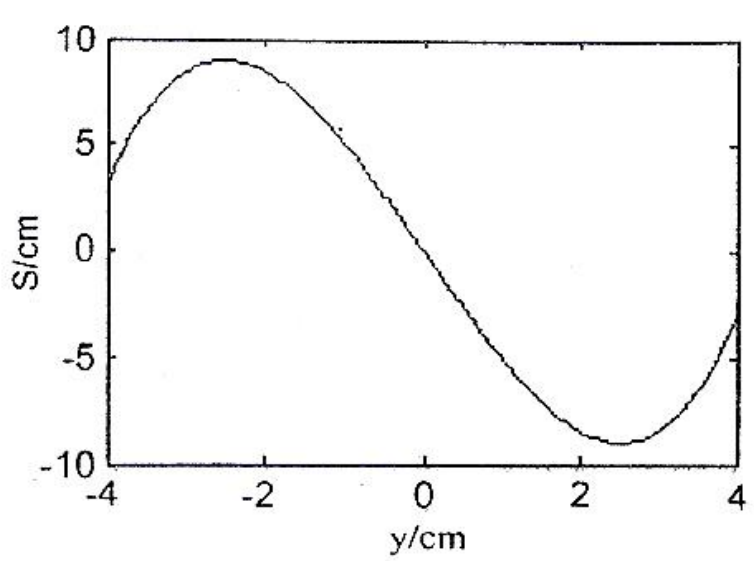

Fig. 7. Ray position on the screen as a function of the position on the cylindrical lens.

figure 7 shows the ray position on the cylindrical lens and the corresponding position on the screen. One can see that for a partial screen, one value has two y values .that is to say two rays on the cylindrical lens with different position will reach the same point on the screen .

A computer program has been constructed to theoretically simulate the interference pattern. From $\mathrm{Eq}(1)$, the OPL has been calculated for both rays, we then calculate the optical path difference $(\Delta)$, which is easily transformed into the phase difference $(\delta)$ by using the relation

$$
\delta=\frac{2 \pi}{\lambda} \Delta
$$

where $\lambda$ is the wavelength of the light used, the intensity distribution can be calculated by the following equation :

$$
I=4 A^{2} \cos ^{2} \frac{\delta}{2}
$$

Where $\mathrm{I}$ is the intensity of the interference fringes and $\mathrm{A}$ is the amplitude of each pair of interference rays .because the distance given by Eq.(1) is a function of the liquid refractive index ,the position of the fringe on the screen is also a function of refractive index of the liquid. to obtain the intensity distribution as an estimated image, we make the maximum intensity $(\delta=0)$ equal 256 , which corresponds to the brightness gray level of the computer monitor used the brightness gray level will be at $\delta$ equal to 0 ,all the other gray values will depend on the cosine value starting from the maximum position on the cylindrical lens to its maximum point the intensity distribution was calculated using equation (1),(11), and (12)which gives a line of pixels 
Military Technical College

Kobry Elkobbah,

Cairo, Egypt

May 29-31,2012

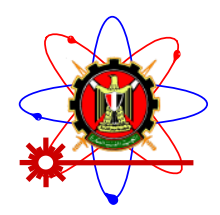

$6^{\text {th }}$ International Conference on

Mathematics and Engineering

Physics (ICMEP-6)

describing the intensity distribution on the screen repeating that line of pixels using the same gray level we can obtain a $2 \mathrm{D}$ array that represent the estimated image of the theoretical interferogram .

Figure (8) is a selected part of the experimental pattern .By using this method we measured the indices of several kinds of liquids.At the same time, we used the Abbe's refractometer to measure their refractive indices .the results are shown in table 1 .one can see that the results of the two methods are very near .
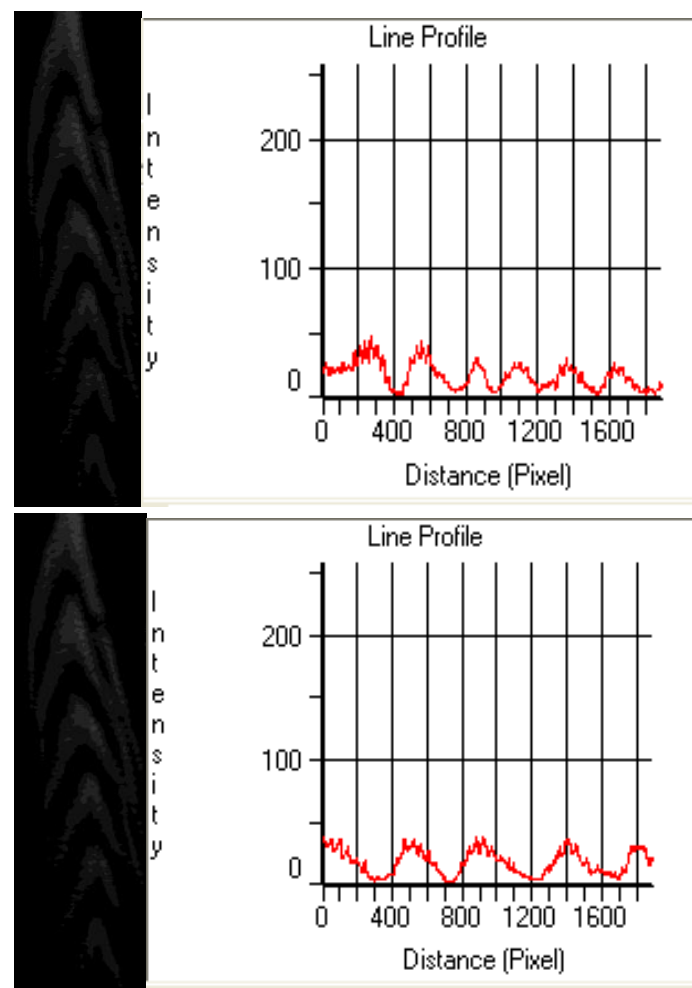

(8)Experimental pattern after digital processing and the intensity changes with experimental fringe position on the screen 
Military Technical College Kobry Elkobbah, Cairo, Egypt May 29-31,2012 $6^{\text {th }}$ International Conference on

Mathematics and Engineering

Physics (ICMEP-6)

Table 1. Reíractive Indices of Abbe Refractometer and Capillary Tube Interferometer Methods ${ }^{\circ}$

\begin{tabular}{lccr}
\hline \multicolumn{1}{c}{ Sample Name } & $\begin{array}{c}n_{1}: \text { Abbe } \\
\text { Refractometer }\end{array}$ & $\begin{array}{c}n_{2}: \text { Capillary } \\
\text { Tube }\end{array}$ & \multicolumn{1}{c}{$n_{1}-n_{2}$} \\
\hline Ethanol & 1.3510 & 1.3540 & -0.0030 \\
Gasoline & 1.4394 & 1.4395 & -0.0001 \\
Carbon & 1.4460 & 1.4463 & -0.0003 \\
$\quad$ tetrachloride & & & \\
$\quad \begin{array}{l}\text { Diesel oil } \\
\text { Mixture of ethanol }\end{array}$ & 1.4604 & 1.4601 & 0.0003 \\
$\quad$ and $\mathrm{CS}_{2}$ & 1.5724 & 1.5724 & -0.0000 \\
Carbon bisulfide & 1.6222 & 1.6273 & -0.0051 \\
\hline
\end{tabular}

${ }^{a}\left(T=30^{\circ} \mathrm{C}\right)$.

\section{Results and discussions:}

Images of the resulting transverse interference patterns for blood samples are shown in figures 4.the patterns comprises of only a few number of interference fringes which were found to be typical for homogenous liquids and could be explained in terms of two-beam type interference between pairs of laser rays passing through different optical media . the interference patterns ,shown in figures 4 corresponding to the transverse fringes of blood samples 
Military Technical College

Kobry Elkobbah,

Cairo, Egypt

May 29-31,2012

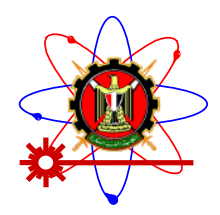

$6^{\text {th }}$ International Conference on

Mathematics and Engineering

Physics (ICMEP-6)

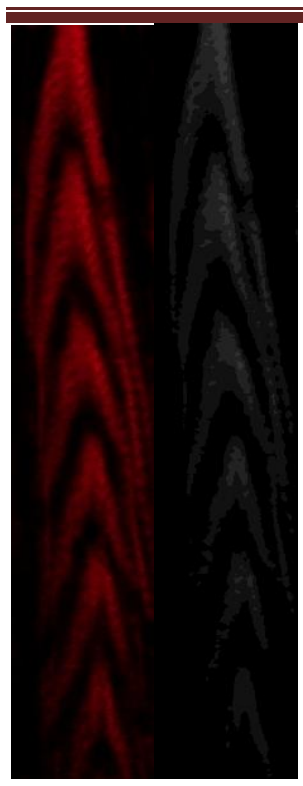

Figures 4 transverse fringes of blood samples

The relation between the fringe order and the deflection angle have been used to find out the exact fringe order referring to the deflection angle values .

A plot of the obtained values of the refractive index as a function of blood samples's haemoglobin concentration, white blood cells concentration ,red blood cells concentration and platelets concentration are shown in figures $6,7,8,9$.

A curve fitting program has been used to obtain the best linear and polynomial fitting . 
Military Technical College

Kobry Elkobbah,

Cairo, Egypt

May 29-31,2012

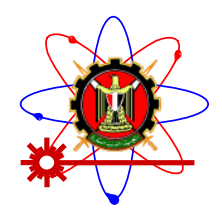

$6^{\text {th }}$ International Conference on Mathematics and Engineering

Physics (ICMEP-6)

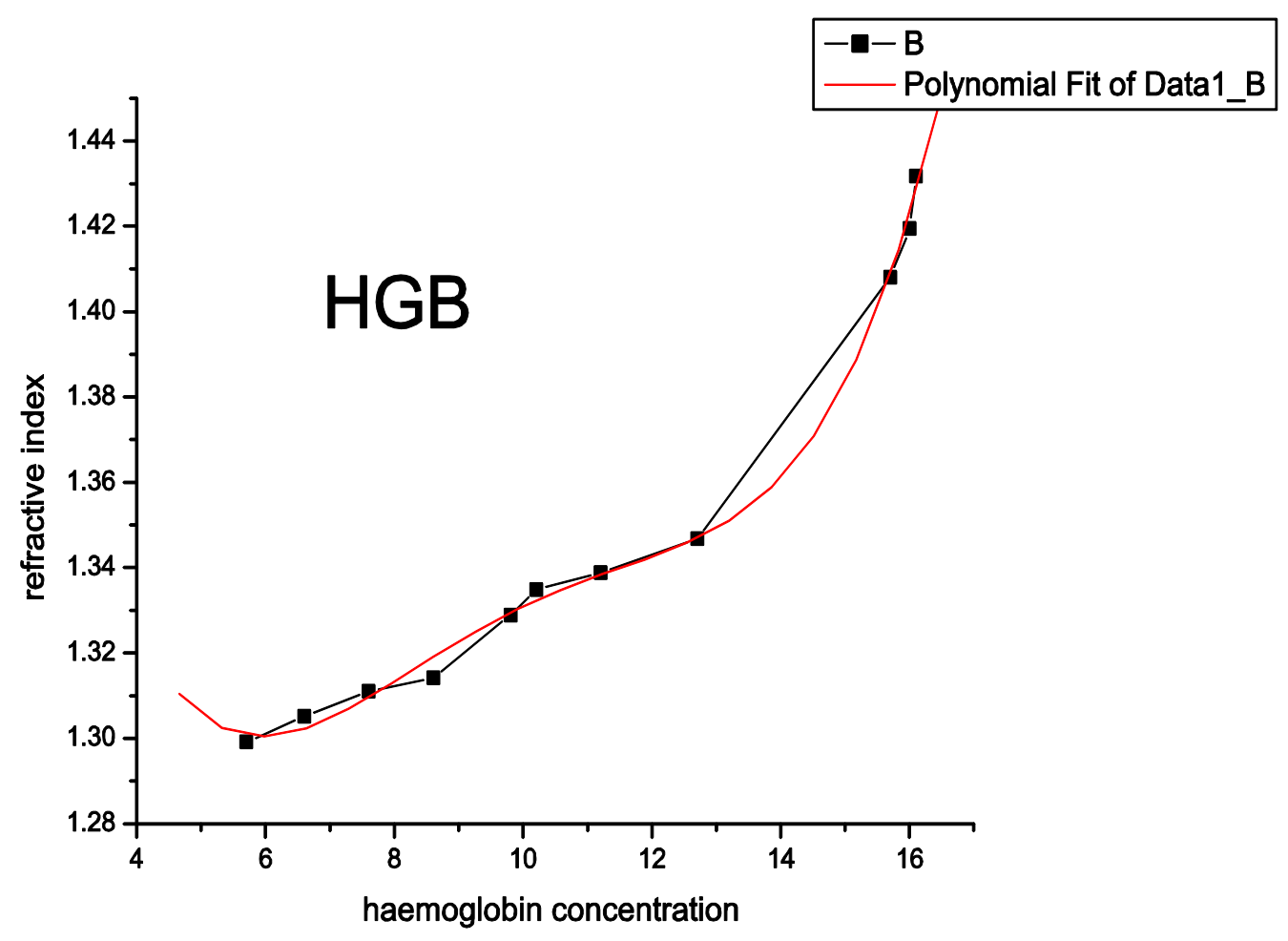

Figure 6 Aplot of the blood sample's refractive's index as

a function of sample's haemglobin concentration

It was found that the polynomial fitting of the forth order gives the best correlation coefficient which equal 0.997

$\mathrm{Y}=\mathrm{A}+\mathrm{B} 1 * \mathrm{X}+\mathrm{B} 2 * \mathrm{X}^{\wedge} 2+\mathrm{B} 3 * \mathrm{X}^{\wedge} 3+\mathrm{B} 4 * \mathrm{X}^{\wedge} 4$ 
Military Technical College

Kobry Elkobbah,

Cairo, Egypt

May 29-31,2012 $6^{\text {th }}$ International Conference on Mathematics and Engineering

Physics (ICMEP-6)

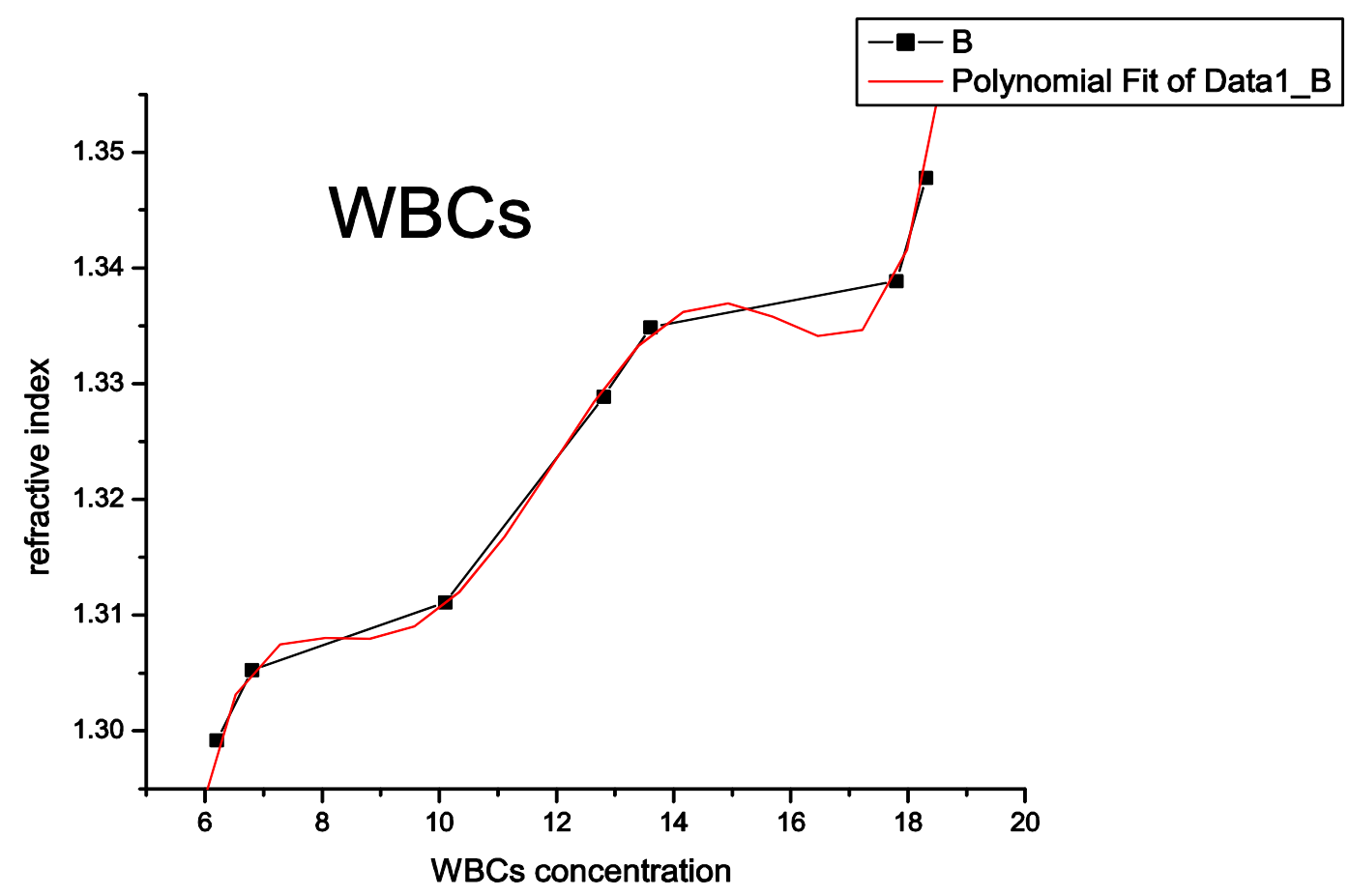

Figure 7 Aplot of the blood sample's refractive's index as

a function of sample's WBCs concentration

It was found that the polynomial fitting of the fifth order gives the best correlation coefficient which equal 0.99949

$\mathrm{Y}=\mathrm{A}+\mathrm{B} 1 * \mathrm{X}+\mathrm{B} 2 * \mathrm{X}^{\wedge} 2+\mathrm{B} 3 * \mathrm{X}^{\wedge} 3+\mathrm{B} 4 * \mathrm{X}^{\wedge} 4+\mathrm{B} 5 * \mathrm{X}^{\wedge} 5$ 
Military Technical College

Kobry Elkobbah,

Cairo, Egypt

May 29-31,2012 $6^{\text {th }}$ International Conference on Mathematics and Engineering

Physics (ICMEP-6)

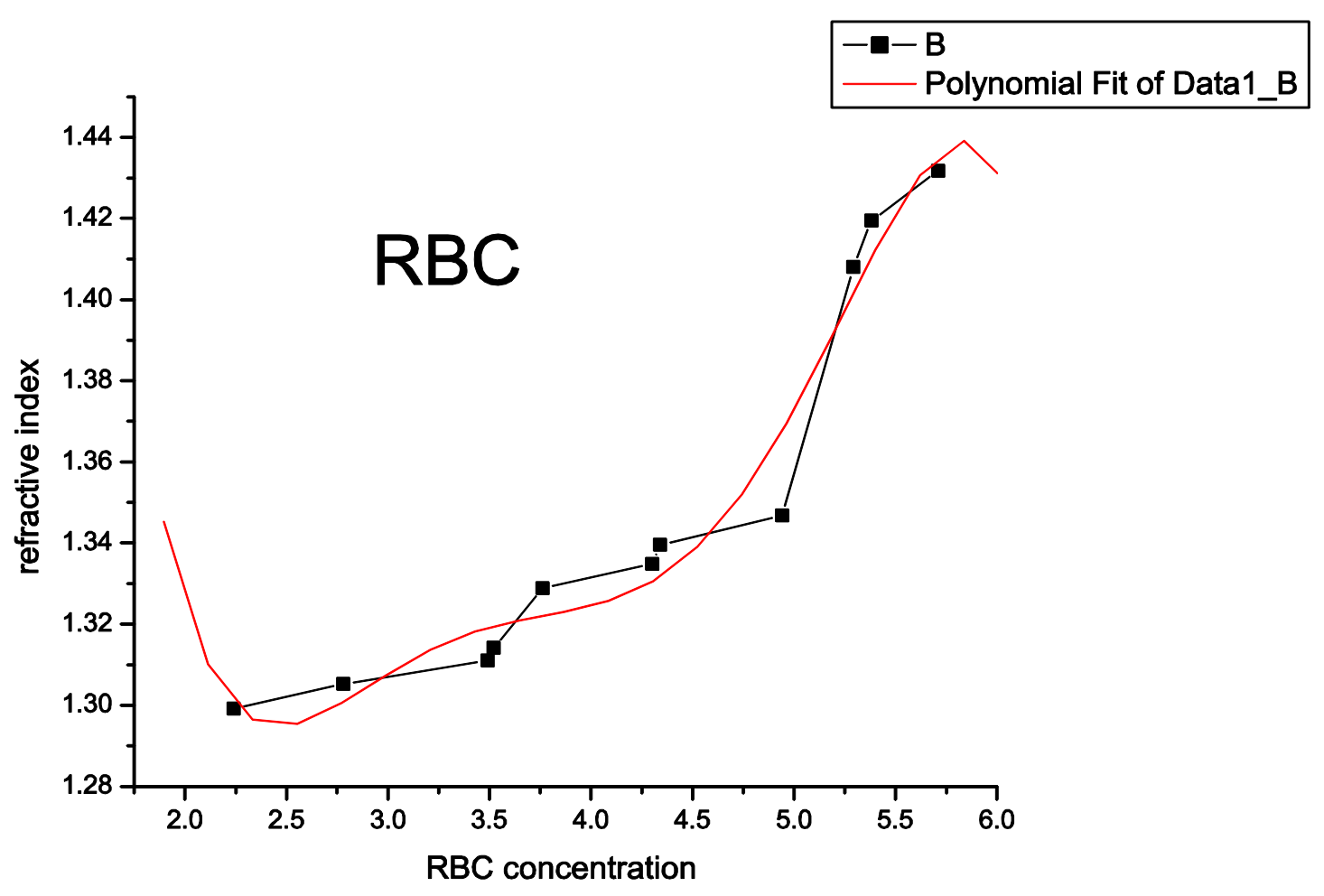

Figure 8 Aplot of the blood sample's refractive's index as

a function of sample's RBCs concentration

It was found that the polynomial fitting of the fifth order gives the best correlation coefficient which equal 0.96445

$\mathrm{Y}=\mathrm{A}+\mathrm{B} 1 * \mathrm{X}+\mathrm{B} 2 * \mathrm{X}^{\wedge} 2+\mathrm{B} 3 * \mathrm{X}^{\wedge} 3+\mathrm{B} 4 * \mathrm{X}^{\wedge} 4+\mathrm{B} 5 * \mathrm{X}^{\wedge} 5$ 
Military Technical College Kobry Elkobbah, Cairo, Egypt May 29-31,2012 $6^{\text {th }}$ International Conference on Mathematics and Engineering Physics (ICMEP-6)

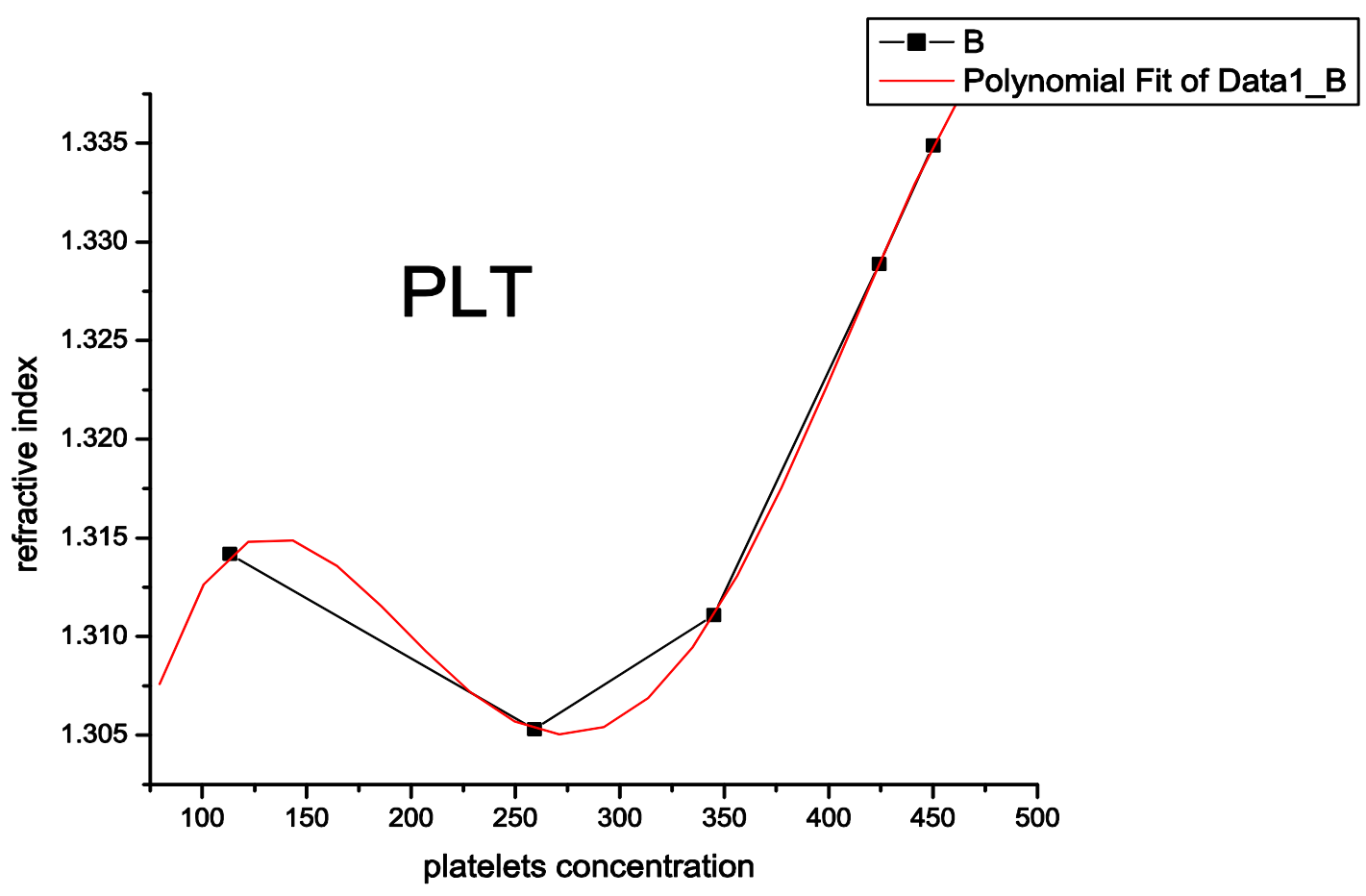

Figure 9 Aplot of the blood sample's refractive's index as

a function of sample's platelets concentration

It was found that the polynomial fitting of the forth order gives the best correlation coefficient which equal 1

$\mathrm{Y}=\mathrm{A}+\mathrm{B} 1 * \mathrm{X}+\mathrm{B} 2 * \mathrm{X}^{\wedge} 2+\mathrm{B} 3 * \mathrm{X}^{\wedge} 3+\mathrm{B} 4 * \mathrm{X}^{\wedge} 4$

It is clear that an increase in the haemoglobin concentration and red blood cells concentration level in blood samples leads to an increase in their refractive indices.the accuracy of the measured refractive indices data depends on the parameters $\varepsilon, \mathrm{y}$ and $\mathrm{r}$, which in turn correspond to displacements that display a $1 / 2 \lambda$ optical path difference $(0.3 \mu \mathrm{m})$.

Finally, it is interesting to note that under the same experimental conditions, the number of transverse interference fringes appearing in the images of the blood samples is found to be considerably fewer than those appearing in the case of optical fibres (Barakat et al.,1983,1987). 
Military Technical College

Kobry Elkobbah,

Cairo, Egypt

May 29-31,2012

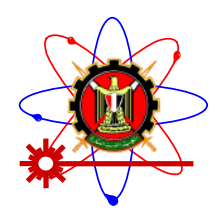

$6^{\text {th }}$ International Conference on

Mathematics and Engineering

Physics (ICMEP-6)

This is due to the fact that in optical fibres the refractive index changes gradually with the radius of the fibre, while in the blood sample this change occurs in more discrete steps .

\section{conclusion}

We used a capillary tube interferometer to measure the refractive indices of liquids. To accurately determine the distance $\mathrm{I}_{1}$ between the plane of the cylindrical lens and the wall of the capillary tube ,two simulated interference pattern of the refractive indices of known liquids were used to fit with their experimental pattern . this increased the accuracy of the experiment from the experimental results we expect that this method can be used to measure a wide range of refractive indices and not cause a problem as in traditional method. For low transmission liquids although the intensity of the transmission rays is weak ,the difference of the OPL of the two interference rays is very slight which means the intensties of the two rays is very near i.e. the contrast of the fringe is good so this technique is also promising as a mean of measuring the refractive indices of low transparent liquids as blood

in this work, the authors present the first attempt to measure haemoglobin concentration in blood samples by measuring their refractive index using a capillary tube laser-lens interferometer the blood sample filling the capillary tube were illuminated by a thin $\mathrm{He}-\mathrm{Ne}$ laser sheet and the resulting transverse interference pattern were projected on a screen whose plane was perpendicular to the laser sheet .

As expected ,the patterns showed bell-shaped fringes as in case of optical fibers except that the number of the fringes in this case was much smaller.the characteristic bell-shape demonstrated mathematically by calculating the optical path difference between a reference ray and a ray that passes through the blood sample the refractive indices of the crude oil samples were determined with accuracy of $5^{*} 10^{-6}$ by measuring the deflection angles of the fringes and then by using equation (17). The high accuracy obtained makes this technique a valuable one for measuring the refractive index of blood sample

In our work we found that as the haemoglobin concentration increases in the blood sample the corresponding refractive index will also increase, and this is also happen with the red blood cells as its amount increase the corresponding refractive index increase .

And based on this relation between the refractive index and haemoglobin concentration in blood demonstrated we wish to have a prototype design in future measure the concentration of 
Military Technical College Kobry Elkobbah, Cairo, Egypt May 29-31,2012

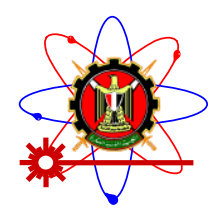

$6^{\text {th }}$ International Conference on

Mathematics and Engineering

Physics (ICMEP-6)

haemoglobin in blood by using a program which convert the refractive index value to a haemoglobin concentration

\section{References}

1. H.El-Ghandoor ,E.Hegazi,I.Nasser,and G.M. Behery, "measuring the refractive index of crude oil using capillary tube interferometer ,"Opt. Laser Technol 35 ,361-367(2003).

2. H.El-Ghandoor,I.Nasser,M.A. Abd-El Rahman , and R.Hassan,theoretical model for the transverse interference pattern of Grin OPTICAL fiber using a Laser sheet of light ,'Opt.Laser Technol .32,281-286(2000).

3. Ailing Yang, Wendong Li, Guang Yuan, Junyu Dong, and Jinliang Zhang "measuring the refractive indices of liquids with a capillary tube interferometer "APPLIED OPTICS November 2006 Vol.45,No.31

4. H.El-Ghandoor, I.Nasser ,A.Abdel-Hady,and A.Al-Shukri" a comparation study of spliced optical fibers ," Opt. Lasers Eng.41,277-287(2004).

5. Hamza, M.A.Mabrouk, W.A.Ramadan and H.H.Wahba,"core index determination of a thick fiber using lens fiber interference (LFI) technique," Opt.Lasers Eng.42,121130(2004).

6. W.A.Ramadan,"on-line lens fiber interference method for testing a thick fiber, ,J.Opt.A 2,234,238(2000).

7. M..Fukuta,T.Yanagisawa,S.Miyamura, and Y.Ogi,"concentration measurement of refrigerant oil mixture by refractive index ,'Int.J.Refrig .27,346-352(2004).

8. N.Barakat, H.A. El-Hennawi, E.Abd. EL-Ghafar,H. El-Ghandoor,R,Hassan,and F.ElDiasty,"three-dimensional refractive index profile of aGRIN optical waveguide using multiple beam interference fringes,"Opt.Commun. 191,39-47(2001).

9. A.A. Hamza, M.A.Mabrouk, W.A.Ramadan, and M.A.Shams-Eldin,"Determination of GRIN optical fibre parameters from transverse interferograms considering the refraction of the incident ray by the fibre, "Opt.Common .200 , 131,138 (2001).

10. M.A.El-Morsy ,T.Yatagi, A. A. Hamza, M.A.Mabrouk, and T.Z.N.Sokkar,"automatic refractive index profiling of fibers by phase analysis method using fourier transform ,'Opt.Lasers Eng.38,509-525(2002). 
Military Technical College Kobry Elkobbah, Cairo, Egypt May 29-31,2012

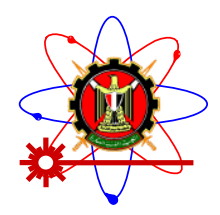

$6^{\text {th }}$ International Conference on Mathematics and Engineering Physics (ICMEP-6)

11. M.A.El-Morsy, K.Harada, M.Itoh , and T.Yatagai ,"A sub-fringe integration method for multiple-beam Fizeau fringe analysis ,"Opt.Laser Technol.35,223-232(2003).

12. KS. Approach to the anemias. In: Goldman L, Ausiello D, eds. Cecil Medicine. 23rd ed. Philadelphia, Pa: Saunders Elsevier; 2007:chap 162. Bablock w.et al.(1988)'A general regression procedure for method transformation ',J.Clin Chem.Clin.Biochem ., Vol.26,pp.783-790.

13. Bracewell,R.(1978)The Fourier and its Applications,p.262,McGraw-Hill,New York .

14. Alleyne M, Horne MK, Miller JL. Individualized treatment for iron-deficiency anemia in adults. Am J Med. 2008 Nov;121(11):943-8.

15. Antony AC. Megaloblastic anemias. In: Goldman L, Ausiello D, eds. Cecil Medicine. 23rd ed. Philadelphia, Pa: Saunders Elsevier; 2007:chap 170.

16. Ginder GD. Microcytic and hypochromic anemias. In: Goldman L, Ausiello D, eds. Cecil Medicine. 23rd ed. Philadelphia, Pa: Saunders Elsevier; 2007:chap 163.

17. Killip S, Bennett JM, Chambers MD. Iron deficiency anemia. Am Fam Physician. 2007 Mar 1;75(5):6718. 